\section{HANDREARING OF JACKAL (CANIS AUREUS) AT MAHARAJBAG ZOO, NAGPUR}

\section{V.M. Dhoot, S.V. Upadhye, R.M. Zinjarde and M.R. Pande}

Maharajbag Zoo, College of Agriculture, Nagpur, Maharasthra, India.

The successful handrearing of four jackal cubs (Canis aureus) at Maharajbag Zoo, Nagpur is presented here. A female jackal delivered eight cubs in the morning hours on 4 April 2001. Considering the large litter size, it was decided to separate four cubs ( 2 males \& 2 females) from the mother and rear them separately. The remaining four cubs were left with the mother. The care and management of the hand-reared cubs was done as follows.

The four cubs were kept in a separate enclosure, which was well protected from high temperature. The feed and medication offered to these cubs is given in Table 1. Lukewarm cow milk was given through sterilized feeding bottles. Multivitamin and iron preparations along with calcium supplementation were given in required quantities. The frequency of feeding was reduced from six times a day to once a day gradually. However, feeding
Table 2. Average growth rate of cubs

\begin{tabular}{lllllll}
\hline $\begin{array}{l}\text { Age } \\
\text { (days) }\end{array}$ & $\mathbf{1}$ & $\mathbf{2}$ & $\mathbf{3}$ & $\mathbf{4}$ & Mean body & Weight gain \\
\hline 3 & 102 & 105 & 105 & 100 & 107.50 & - \\
7 & 100 & 106 & 105 & 105 & 104.00 & $(-) 3.50$ \\
14 & 125 & 120 & 120 & 125 & 122.50 & 18.50 \\
21 & 155 & 150 & 155 & 150 & 152.50 & 30.00 \\
28 & 180 & 180 & 160 & 150 & 167.50 & 15.00 \\
35 & 200 & 205 & 210 & 210 & 206.25 & 38.75 \\
42 & 250 & 260 & 280 & 290 & 270.00 & 63.75 \\
49 & 345 & 350 & 340 & 345 & 345.00 & 75.00 \\
56 & 475 & 415 & 405 & 440 & 433.75 & 88.75 \\
63 & 525 & 520 & 525 & 535 & 526.25 & 92.50 \\
70 & 620 & 630 & 625 & 615 & 622.50 & 96.25 \\
77 & 725 & 745 & 750 & 760 & 745.00 & 122.5 \\
84 & 860 & 870 & 865 & 865 & 865.00 & 120.00 \\
90 & 1005 & 990 & 960 & 1030 & 996.25 & 131.25 \\
\hline & & & & & &
\end{tabular}

was not allowed during night hours (between $2200 \& 0600 \mathrm{hr}$ ). The cubs were under close observation during the entire period. Body growth was assessed by recording body weight at weekly intervals (Table 2).

The cubs were offered undiluted cow's milk at frequent intervals.

Table 1. Feeding schedule of Jackal cubs

\begin{tabular}{lllllll}
\hline $\begin{array}{l}\text { Age } \\
\text { in weeks }\end{array}$ & $\begin{array}{l}\text { Avg. milk } \\
(\mathbf{m l}) / \text { cub/day }\end{array}$ & $\begin{array}{l}\text { Avg. chicken } \\
\text { soup (ml)/cub }\end{array}$ & $\begin{array}{l}\text { Eggl } \\
\text { cub }\end{array}$ & $\begin{array}{l}\text { Beefl } \\
\text { cub (g) }\end{array}$ & $\begin{array}{l}\text { Frequency of } \\
\text { feeding }\end{array}$ & Remarks \\
\hline 1 & 30 & - & - & 6 & $\begin{array}{l}\text { Zincovit drops 3, Ferium drops 2 for 15 days. } \\
\text { Double dose in next fifteen days. } \\
2\end{array}$ \\
\hline & 40 & - & - & 6 & $\begin{array}{l}\text { Ascal liquid 3ml OD x 15 days 5ml OD up } \\
\text { to 12 weeks. }\end{array}$ \\
3 & 55 & 5 & - & - & 5 & - \\
4 & 60 & 10 & 1 (boiled) & - & 4 & - \\
5 & 60 & 10 & 1 (boiled) & Boiled kheema 20 & 4 & - \\
6 & 60 & 10 & 1 (boiled) & Boiled kheema 30 & 3 & - \\
7 & 50 & 10 & 2 (boiled) & Boiled kheema 30 & 3 & - \\
8 & 50 & 20 & 2 raw & Raw kheema 30 & 3 & - \\
9 & 25 & 30 & 2 raw & Raw kheema 40 & 3 & - \\
10 & 25 & 30 & 2 raw & Raw kheema 60 & 3 & - \\
11 & 25 & 30 & 2 raw & Raw kheema 75 & 2 & - \\
12 & - & 30 & 2 raw & Raw kheema 100 & 1 & - \\
\hline \hline
\end{tabular}


The quantity of milk was gradually increased up to the fourth week and reduced from the sixth week onwards. Similarly, chicken soup was offered from the third week and its quantity was increased gradually up to the ninth week. One boiled egg was introduced in the diet from the fourth week and subsequently two raw eggs were given from the tenth week. The cubs were fed boiled beef (boneless) from the fifth week gradually increasing the quantity. Raw kheema was offered from the eighth week. The cubs were introduced to the other cubs after 12 weeks.

The handreared cubs were readily accepted by the other four cubs that were with the mother, when introduced. However, the mother showed some aggression and disinclination towards the hand-reared cubs for the first 2-3 days, but later accepted them.

Occasionally handrearing is practised in zoos to prevent mortality in young ones. The normal litter size in Jackal is three (Acharjyo \& Mohapatra, 1980), but in the present case, the Jackal had a large litter size ( 8 cubs). The possibility of each cub receiving less milk was considered and it was thought necessary to wean four cubs and handrear them separately. Successful handrearing of wild animals in zoos have been reported by several workers such as Mahodaya (1990), Suklikar et al. (1991), Saha et al. (1992) and Dhoot et al. (2000).
Batwe (1987) recommended diluted toned milk with $3.0 \%$ fat and 8.5\% SNF for Hyena cubs. However Rao et al. (1995) successfully reared Hyena cubs with cow milk. In the present case also, undiluted cow's milk was offered to the cubs without any adverse effect.

All the cubs showed normal growth and health as seen from Table 2 .

\section{References}

Acharjyo L.N. and S. Mohapatra (1980). Litter size of some captive wild animals. Journal of the Bombay Natural History Society 77(2): 321-325.

Batwe K.D. (1987). Hand rearing of Hyena in captivity. Zoo's Print June-July: 3.

Dhoot, V.M., S.V. Upadhye and M.R. Pande (2000). Successful hand rearing of Leopard cub at Maharajbag Zoo. Zoo's Print Journal 5(11): 13.

Mahodaya, A.K. (1990). Diary of handrearing of Leopard cub at Indore Zoo. Zoos' Print 5 (11): 13.

Rao, M.J., M. Sekar and P. Asaithambi (1995). Growth rate of handreared Striped Hyaena cub (Hyaena hyaena) at AAZP, Vandalur, Madras. Zoo's Print 10(9): 31.

Saha, G.R., B.K. Majumdar and B.D. Biswas (1992). Successful handrearing of an African Lion cub (Panthera leo leo) in Alipur Zoo, Calcutta. Zoo's Print 7(12): 22-23.

Suklikar, S.B., D.B. Sarode and S.V. Gorde (1991). Care and management of Tiger cubs in zooZoos' Print 6(11): 27.

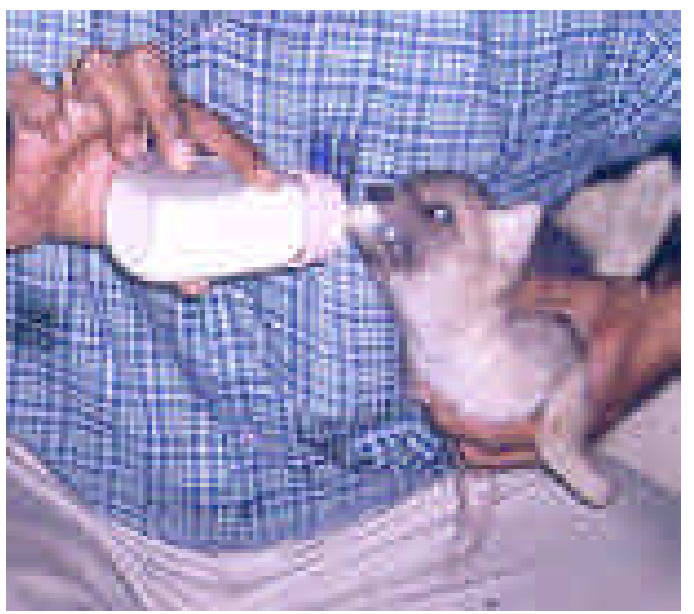

